\title{
O PROFORMAÇÃO E SEU MODELO DE EDUCAÇÃO A DISTÂNCIA
}

\author{
Raquel de Almeida Moraes*
}

UNB

\section{RESUMO}

O artigo analisa o modelo de educação a distância adotado pelo Programa de Formação de Professores Leigos, PROFORMAÇÃO utilizando o método do materialismo histórico e dialético que articula as contradições no movimento da totalidade histórica. A sua conclusão destaca que no seu modelo educacional há um vínculo direto entre educação e produção capitalista, que prioriza as competências e habilidades técnicas ao invés do conhecimento e ética política, mediante a metodologia do "aprender a aprender" e da pedagogia das competências acentuando, no entanto, a alienação do professor-trabalhador. Palavras-Chave: Política de Educação a Distância; PROFORMAÇÃO; Modelos Educacionais; Banco Mundial.

\section{THE PROFORMAÇÃO AND ITS MODEL OF DISTANCE LEARNING}

\begin{abstract}
The paper analyzes the model of distance learning adopted by the Teacher Training Program, PROFORMAÇÃO using the method of historical and dialectical materialism that articulates the contradictions in the movement of the whole history. Its conclusion points out that in its educational model there is a direct link between education and capitalist production, which prioritizes the competences and technical skills rather than knowledge and ethics policy, through the methodology of "learning to learn" and the pedagogy of competences accentuating, however, the teachers's alienation.

Keywords: Distance Education Policy; PROFORMAÇÃO; Educational Models; World Bank.
\end{abstract}

\section{Introdução}

A Educação a Distância, EAD, foi formalizada como uma das políticas educacionais brasileiras a partir da criação da secretaria de Educação a Distância, SEED, na estrutura administrativa do Ministério da Educação, MEC, em 1996 pelo então ministro da educação Paulo Renato de Souza, do Governo Fernando Henrique Cardoso, do Partido da Social Democracia Brasileira, PSDB.

Dentro do agora extinto SEED/MEC ${ }^{1}$ destacava-se o Programa de Formação de Professores Leigos, PROFORMAÇÃO, que foi criado, segundo os documentos oficiais, em 1999, como curso de nível médio, com habilitação em magistério, na modalidade de educação a distância, para formar docentes que exercem a profissão sem habilitação legal nas escolas públicas do Norte, Nordeste e Centro-Oeste. O curso tem duração de dois anos (3.200 horas) e utiliza material impresso e video.

O objetivo é fazer uma análise crítica do modelo educacional utilizado nesse programa de formação para o trabalho docente. Tendo como fontes primárias: documentos, materiais, cursos on-line $e$ videos obtidos, tanto em pesquisa on-line como em campo por estudantes sob nossa orientação, no SEED/MEC, analisamos o PROFORMAÇÃO entre 
1999-2006, utilizando o método do materialismo histórico e dialético. Para isso, contrapomos dados e analistas no intuito de detectar o sentido geral de seu modelo educacional por trás das aparências discursivas.

\section{O PROFORMAÇÃO nos governos FHC e Lula}

Oficializado em 1999 na gestão do ministro da educação Paulo Renato de Souza do governo Fernando Henrique Cardoso - FHC (1995-2002) e continuada, sem alterações, no governo de Luis Inácio Lula da Silva (2003-2010), o Programa de Formação de Professores em Exercício, PROFORMAÇÃO foi um dos programas da Secretaria de Educação a Distância, SEED, em conjunto com a Secretaria de Ensino Fundamental, SEF, voltado para a formação à distância do professor leigo em Magistério de nível médio, que atua nas quatro primeiras séries do ensino fundamental e nas classes de alfabetização e préescola nas regiões Norte, Nordeste e Centro-Oeste do Brasil. Na atualidade está formando professores no Timor Leste.

Foi financiado pelo Fundo de Desenvolvimento da Escola ${ }^{2}$, FUNDESCOLA até 2003. Por sua vez, o programa contava com recursos provenientes do FUNDEF (Fundo de Manutenção e Desenvolvimento do Ensino Fundamental e Valorização do Magistério), do FNDE (Fundo Nacional da Educação) e do BM (Banco Mundial, instituição financeira criada em 1944, como resultado da conferência de Bretton Woods ${ }^{3}$ ). A partir de 2004, o PROFORMAÇÃO tem contado com recursos provenientes do orçamento do próprio Ministério da Educação, MEC.

De acordo com dados do Censo Escolar do Instituto Nacional de Estudos e Pesquisas Educacionais (MEC/INEP, 2003), em 2002 foi registrado um total de 2,4 milhões de funções docentes em Creche, Pré-escola, Classe de Alfabetização, Ensino Fundamental e Ensino Médio, para um total de 50,6 milhões de alunos matriculados nesses níveis de ensino.

Para o MEC/INEP (2003), desses 2,4 milhões de docentes, em 1999 existiam 68.855 professores não-habilitados ou leigos, correspondendo a 2,87\% dos professores que atuavam em classes de alfabetização e de $1^{\mathrm{a}}$ a $4^{\mathrm{a}}$ séries do Ensino Fundamental, nos quinze estados que aderiram ao PROFORMAÇÃO, a saber: Acre, Alagoas, Amazonas, Bahia, Ceará, Goiânia, Maranhão, Mato Grosso, Mato Grosso do Sul, Paraíba, Pernambuco, Piauí, Roraima, Sergipe, Tocantins. Até julho de 2002 esse programa habilitou em Magistério de nível médio 23.700 professores, ou seja, $35 \%$ da demanda, restando ainda 45.155 professores para serem capacitados. A partir de julho de 2004 na fase IV do programa, as regiões Sul e Sudeste também foram integradas.

O terceiro Grupo do PROFORMAÇÃO teve início em Julho de 2002 e término em Junho de 2004. Com ele foi seguida a mesma fórmula dos grupos anteriores e houve uma maior adesão de estados ao referido programa.

Em 2009, segundo dados do INEP/MEC divulgados pelo Portal IG de 04/06/2010, o número de professores leigos no país passou para 152.454, representando 7,7\% dos docentes. Segundo a reportagem, "em 2007, 103.341 professores brasileiros estavam nessa situação. No ano passado, eles somavam 139.974. O aumento chega a 35,4\% em dois anos". Considerando que em 2002 a quantidade para ser formada era de 45.155, em 2009 esse número triplicou, o que coloca grandes desafios para as políticas públicas.

Nas tabelas abaixo vemos a distribuição em 2006 dos professores com formação apenas do ensino fundamental, e damos destaque para os professores leigos que ensinam no nível médio, o que é uma distorção. 


\begin{tabular}{|c|c|}
\hline $\begin{array}{c}\text { Funções Docentes com formação } \\
\text { Fundamental completa - Ano 2006 }\end{array}$ & $\begin{array}{c}\text { Total: } \\
\mathbf{2 2 . 6 1 8}\end{array}$ \\
\hline Leciona em Creche & 4.918 \\
\hline Leciona em Pré-Escola & 6.343 \\
\hline Leciona na Educ Especial & 343 \\
\hline Leciona na Alfab - J/Adultos & 0 \\
\hline Leciona de $1^{\text {a }}$ a $4^{\text {a }}$ Sér - J/Adultos & 1.742 \\
\hline Leciona de $5^{\text {a }}$ a $8^{\text {a }}$ Sér - J/Adulto & 192 \\
\hline Leciona Ensino Médio - J/Adultos & 2 \\
\hline
\end{tabular}

Fonte: Pesquisado a partir dos dados disponíveis no MEC/INEP, 2011

\begin{tabular}{|c|c|}
\hline $\begin{array}{c}\text { Critério se seleção: } \\
\text { Funções Docentes com formação Fundamental completa }- \\
\text { Ano: 2006 }\end{array}$ & Total - 22.618 \\
\hline Abrangência_Geográfica & Leciona no Ensino Médio \\
\hline Brasil & 22 \\
\hline Alagoas & 1 \\
\hline Ceará & 2 \\
\hline Mato Grosso do Sul & 4 \\
\hline Paraíba & 5 \\
\hline Rio Grande do Sul & 3 \\
\hline Roraima & 1 \\
\hline Santa Catarina & 5 \\
\hline Tocantins & \\
\hline
\end{tabular}

Fonte: Pesquisado a partir dos dados disponíveis no MEC/INEP, 2011 
Com duração de dois anos, o PROFORMAÇÃO é desenvolvido em quatro módulos, um por semestre. Cada módulo compreende fase presencial e fase à distância. $\mathrm{Na}$ fase presencial, os cursistas têm dez dias de aulas presenciais com os professores formadores, nas Agências Formadoras (AGF). A cada quinze dias, aos sábados, ocorrem os encontros com o tutor. E ao final de cada bimestre, é feita uma avaliação escrita. Na fase à distância, os cursistas estudam individualmente, utilizando o "material didático autoexplicativo" que recebem e aplicam em sala de aula o que estão aprendendo, registrando em um memorial suas experiências.

O "material didático autoexplicativo" é composto por vídeos e impressos, como guias de estudo e cadernos de verificação da aprendizagem. As Agências Formadoras utilizam a informática para fazer o cadastramento, o monitoramento e o registro da avaliação do desempenho dos participantes. Com a introdução e generalização do MOODLE ${ }^{4}$ no país, observou-se que há o uso também das possibilidades dessa plataforma de E-Learning nos seus cursos em diversos estados.

Segundo observação e depoimentos, a elaboração desse material foi permeada por contradições entre a equipe de professores das Universidades Brasileiras e os representantes do Banco Mundial, os quais acabaram dando a palavra final.

\section{Discursos e contradições}

$\mathrm{Na}$ avaliação do especialista inglês em ensino a distância e consultor do Banco Mundial no PROFORMAÇÃO, Michael Moore (MORAES, 2001, p.108), um dos grandes méritos desse programa é possibilitar o aprendizado ligado ao cotidiano dos professores. "Todo processo de aprendizagem que relaciona o conhecimento adquirido com a realidade do aluno é mais proveitoso".

O consultor também defendeu o uso exclusivo de textos e vídeos como instrumentos pedagógicos apesar da existência de tecnologias mais modernas como a Internet. "Poderemos incorporar os novos meios no futuro, mas enquanto não existir uma rede forte e disponível, eles permanecerão pouco eficazes", argumentou. (idem, ibidem).

Moore (idem, ibidem) ressaltou ainda o papel do instrutor no PROFORMAÇÃO. "Os tutores são os responsáveis por ajudar o aluno individualmente para que ele possa converter informação em conhecimento". O papel desses profissionais consiste, então, em observar e respeitar o ritmo e a bagagem trazida por cada aluno dando o suporte necessário. Moore (idem, ibidem) classificou como boa a experiência das universidades brasileiras com a produção de materiais de ensino a distância. "A vontade política do Governo Federal em investir neste setor, criando uma rede nacional, também é um fator decisivo para que se alcance bons resultados em programas como o PROFORMAÇÃO”.

No que se refere ao tipo de formação docente que o PROFORMAÇÃO propicia Scaff (2000, p. 131), contudo, argumenta que

[...] parece oportuno oferecer cursos de formação de nível Secundário (como é o caso do Projeto PROFORMAÇÃO) e treinamentos esporádicos que garantam ao professor um mínimo de conhecimento do conteúdo a ser ensinado e, principalmente, das técnicas didáticas que garantam o desenvolvimento de um trabalho que atenda às necessidades estabelecidas por esses organismos, sem maiores questionamentos. (grifos nossos) 
No entanto, a análise de Placco, Marli e Gatti (Brasil, 2003, p. 202) afirma que "verificou-se que a maioria dos professores-cursistas não só concluiu o curso, como este se entrelaçou com suas vidas e experiências profissionais. Desse entrelaçamento deriva-se a efetividade e a possibilidade de um impacto que perdure no futuro desses profissionais". E extrai os seguintes depoimentos do Relatório de Avaliação do Programa realizado realizado pelas autoras (BRASIL, 2003, p.202):

Como profissional seria hipócrita se dissesse que não cresci, pois passei a entender melhor o meu aluno, respeitando a individualidade de cada um, adquiri o hábito de ler mais, e obtive bons rendimentos na minha prática pedagógica com aulas mais dinâmicas. Aprendi a expor minhas idéias, enfim, foram vários conhecimentos obtidos. Tudo isso leva-me a ter certeza que o curso tem sido de grande influência nessas mudanças e conhecimentos obtidos, creio que ao final do mesmo sairei não só com um diploma, mas sim, como uma profissional qualificada convicta do que irei fazer. (Cursista, Cruzeiro do Sul, Acre, p.20)

Hoje vejo que professor tem que trabalhar porque é um profissional. E que ele tem que se capacitar para melhor ensinar, para ter um salário maior, para ser visto e reconhecido pelo seu talento e capacidade. Professor tem que ser livre para falar de liberdade para seus educandos. E o Proformação tem alargado esta visão, fazendo com que me sinta importante e capaz, é só querer. (Cursista, Quixadá, Ceará, p.19)

[...] antes, eu não tinha o pensamento de enfrentar uma faculdade. Nestes dois anos, eu me acostumei a estudar e é isso que me dá força para continuar... (Cursista, Quixadá, Ceará, p.28)

Já a pesquisa de Augusto (2005, p. 146) destaca o seguinte depoimento:

E a mensagem que eu deixo sobre o PROFORMAÇÂO é que ele foi e é, porque está vivo dentro de cada um que fez, na só o livro mas uma bíblia para cada um seguir cada dia, porque ele deixou história e ele deixou raízes, raízes para dar bons frutos, boas árvores e dessas árvores dar bons frutos [...] (Cursista, Formosa, Goiás).

Para o autor, referências semelhantes a essas são também encontradas nos memoriais e analisa:

Como se pode observar, a formação a que esteve submetida essa professora pode te-la capacitado tecnicamente, porém sua capacidade de crítica fica reduzida ao ver os livros do PROFORMAÇÃO como uma bíblia que deve ser seguida por todos. (idem, ibidem).

No livro de sua tese de doutorado, Andrade (2011) argumenta que apesar dos limites, o PROFORMAÇÃO foi fundamental para a vida das cursistas que o fizeram, pois alimentaram sua autoestima e lhe conferiram uma certificação, algo de que precisavam para continuar a exercer o seu trabalho, já que a legislação a exigia.

No entanto, por sob essa aparente eficiência da política pública está o real modelo da competência, típica do governo Fernando Henrique Cardoso, como observado por Saviani (2007) e que pode ser pode ser confirmado na seguinte passagem de CAPITU, gestora estadual do PROFORMAÇÃO: 
Uma coisa que eu observava muito na ficha de acompanhamento é a questão das competências, que estão lá no guia do tutor, que estão lá nos livros.Cada material daquele que a gente trabalha tem uma competência a atingir. [...]Então, essas capacidades que o programa adota são uma referência, porque o tutor não vai para a prática pedagógica só porque vai fazer uma visita ao cursista, mas ele vai observar uma competência que está descrita no papel e que tem que ser incorporada na prática do cursista [CAPITU, gestora estadual]

Nossa hipótese sinaliza que o modelo das competências é o adotado no PROFORMAÇÃO e como salienta Saviani (2007), o modelo toyotista, diferente do fordismo, procura "capturar, para o capital a subjetividade dos trabalhadores". (idem, p. 438) que acaba vestindo "a camisa da empresa".

Quanto à gestão, conforme Belloni (1999), percebe-se que ela é centralizada no MEC, pois este é o provedor centralizado de onde partem os materiais e a coordenação geral. No PROFORMAÇÃO, essa gestão, conforme foi analisado por Andrade (2011) se deu em forma de rede, articulando Ministério, secretarias estaduais, municipais e chegando até a ponta que são o professor e o tutor.

Quanto à comunicação, ela também é centralizada e sua ênfase está na produção dos materiais impressos e de vídeos produzido e transmitido pela TV Escola, outro programa em escala nacional. Ambos os programas fazem parte do Planejamento Estratégico do Ministério da Educação do Governo Fernando Henrique Cardoso (BRASIL, 1995) e colocam como estratégico para a formação de professores a combinação do livro didático e a televisão.

Analisando o modelo de avaliação educacional adotado pelo PROFORMAÇÃO, vemos que a massificação do fordismo se faz novamente presente tendo a avaliação no centro do processo, conferindo e controlando a "qualidade" do produto, a saber: se o resultado está de acordo com o modelo apresentado nos módulos e vídeos, sobretudo por meio da Avaliação Prática Pedagógica, onde o cursista tem suas aulas assistidas pelo tutor, como parte integrante do processo avaliativo, conforme dissertação de Augusto (2005) e documento do Processo de Avaliação do PROFORMAÇÃO (BRASIL, 2011).

Relacionando esse fato com a teoria crítica de Avaliação, para Sordi (1998, p.55) temos que:
A margem do trabalho autônomo das instituições se reduz e o controle do seu processo se instala regido pela lógica do mercado. Desta forma, o julgamento dos conhecimentos válidos, socialmente relevantes para serem ensinados via escola, estará nas mãos de uns tantos especialistas, quem sabe distanciados das reais necessidades sociais e do impacto de suas decisões. Usa a pretensa neutralidade da avaliação como anteparo para processar a pasteurização das instituições de modo a que se ajustem ao tipo de escola necessário ao projeto neoliberal.

Quanto à origem do PROFORMAÇÃO, há uma outra contradição. Vejamos.

Segundo Yazbeck (2002), no início dos anos 1960, esteve no Brasil uma missão de assessores estrangeiros provindos de universidades norte-americanas para avaliarem o nosso sistema educacional e, em decorrência, foram criados os seguintes Programas:

1. FUNBEC (Fundação Brasileira para o Ensino de Ciências) - Voltada para as áreas de Matemática, Química e Biologia - Muitos cientistas foram, então, recrutados para trabalhar nos projetos norte-americanos na ótica da Guerra-Fria. 
2. Programa de avaliação nos municípios, inspirado no teste Iowa Basic Skills, na Fundação Getúlio Vargas;

3. Acordos MEC-USAID: que resultaram nas reformas do ensino superior em $1968 \mathrm{e}$ na de primeiro e segundo graus em 1971.

4. E o EDURURAL ou Nordeste 1 (Programa de Expansão e Melhoria do Ensino no Meio Rural no Nordeste Brasileiro, implementado pela Fundação Carlos Chagas e o Banco Mundial).

Tem-se, com o EDURURAL, um dos primeiros programas governamentais em parceria com o Banco Mundial, que trata da educação "rural" ou do campo e o Projeto Logos, Projeto de Capacitação de Professores Leigos, como precursores do atual PROFORMAÇÃO.

No entanto, em artigo postado no Portal da Associação Brasileira de Educação a Distância, ABED BOF; SALGADO; MOORE; MENEZES, RAMOS (2006) afirmam que o histórico do PROFORMAÇÃO data de 1998 e expressa uma conjugação de interesses das secretarias municipais, estaduais e federais de educação para equacionar o que estava posto pelo recém criado Fundo Nacional de Manutenção e Desenvolvimento do Ensino Fundamental e de Valorização do Magistério - FUNDEF que estipulava "a necessidade da habilitação dos professores sem a formação mínima exigida por lei, requerendo da parte dos dirigentes iniciativas no sentido do cumprimento desse dispositivo".

Percebe-se, aqui, um lapso histórico nesses gestores e consultor do BM que contradiz o que MEC e essas secretarias vêm fazendo desde os anos 1970, para combater o problema dos professores leigos, como o Edurural e o Logos. O que estará por trás dessa lacuna?

Barretto (1983) informa que o objetivo do EDURURAL era concentrar esforços na qualificação do professor leigo do ensino do então primeiro grau. Esse professor continuava seus estudos no Projeto Logos II, no nível do Magistério de segundo grau a nível de suplência. No entanto, quando se formavam, essas professoras eram substituídas, conforme a autora sinaliza, dando a entender que as relações políticas de apadrinhamento e clientelismo seriam as responsáveis, já que essas professoras, formadas, receberiam mais e não seria mais conveniente para o município.

Sobre o EDURURAL no nordeste, e em especial no Rio Grande do Norte, Souza (2001), sustenta a tese que além de discriminatória, a proposta não se mostrou suficiente para melhorar os problemas internos da própria educação ministrada no meio rural. Seu argumento se fundamenta nos depoimentos dos técnicos e professores que participaram da experiência e que a avaliaram como sendo um fracasso.

À luz da categoria participação, Souza (2001) analisa as respostas das entrevistas sobre a proposta implementada e encontra coincidência em torno da não participação de grande parte na sua elaboração, como se pode depreender a seguir: "Não é da minha lembrança que nós tenhamos participado da elaboração da proposta. A coisa chegou prá gente como algo já pronto, que tinha de ser implementado (TSME $2^{5}$ ).” (p. 173)

Para o autor, essa pouca participação (embora tenha sido proclamada no discurso) foi a forma como essa política educacional se expressou concretamente e indica, por sua vez, "o interesse do Estado em prolongar por mais algum tempo a permanência do regime autoritário, em crise" [...]. E conclui que o: "objetivo principal do EDURURAL, e evidentemente não explícito, foi alcançado ao transferir US\$ 92 milhões para as mãos de políticos a um seleto grupo de funcionários públicos do Nordeste” (p. 233). 
No entanto Souza (2001) ressalta que essa mesma política teve, contraditoriamente, como saldo positivo engendrar, mesmo com limitações, as bases do desenvolvimento de uma ação educativa com uma perspectiva crítica e transformadora, a qual se constituiu "em uma novidade para a rotina burocrática e uma parte dos funcionários públicos, já habituados nos procedimentos e diretrizes pedagógicas de cunho meramente tecnicistas."(p. 234)

Voltando ao PROFORMAÇÃO, Bof et al (2011) afirmam que:

No Programa, a educação é vista como um processo construtivo e permanente, que vai da vida para a escola e da escola para a vida, articulando conhecimentos formalmente estruturados e saberes adquiridos com a prática. Tem caráter histórico e cultural, formando as novas gerações de acordo com as necessidades da sociedade e, ao mesmo tempo, promovendo a auto-realização e o desenvolvimento das pessoas. São atribuição e responsabilidade de múltiplas agências: a família, a igreja, a empresa, o sindicato, a associação profissional e, é claro, a escola.

Analisando essa concepção, percebe-se que a escola fica em último lugar, como se o ensino escolar fundamental não fosse dever do Estado e direito público subjetivo (LDB artigo $5^{\circ}$ ). Adiante no texto os autores mencionam que essa concepção orienta a valorização da experiência extracurricular do professor-cursista, omitindo, no entanto, a orientação do Banco Mundial que preconiza a aprendizagem ao longo da vida (WORLD BANK, 2003) para se viver na contemporaneidade da economia do conhecimento.

Apesar da crise do fordismo, tanto na economia quanto na educação, o Banco Mundial, contraditoriamente, continua utilizando a lógica do modelo taylorista-fordista em EAD impondo-o para os países periféricos. É notório observar essa lógica no planejamento e no desenho dos materiais autoinstrucionais, onde um mesmo discurso está presente nos livros e vídeos utilizados no Ceará, em Mato Grosso, Goiás, Pará etc., como se todos os cursistas tivessem a mesma realidade (MORAES \& LIMA, 2005 e MORAES, 2003).

Sobre isso Gatti (2003) e os demais avaliadores do programa se omitem. A nosso ver, a origem da problemática da formação do professor leigo no Brasil não pode ser tratada de forma idealista, como se isso fosse um assunto simplesmente técnico ou psicosocial e não político-econômico em sua totalidade, movimento e contradição (MARX, 1971).

Kawamura (1986, 1990) pontua que no Brasil, após a II Guerra Mundial, a perspectiva tecnocrática perpassa todo o aparato educacional e as políticas sociais passam a se subordinar aos parâmetros técnicos em uma estrutura político-administrativa organizada de forma a privilegiar a instância técnica e conferir poder aos técnicos da educação.

Atualizando o debate na contemporaneidade, Silva Junior et Al (2010, p. 44) argumentam que de um Estado fordista e de bem-estar social nos anos 1930 passamos ao Estado gestor dos anos 1990, um Estado modernizado "voltado para a reprodução do capital e de elaboração de políticas sociais a serem desenvolvidas no âmbito da sociedade civil , ainda que sob seu controle e avaliação".

Dessa forma, os autores assinalam que a reforma também atinge a Educação e é orientada "por uma ciência que se tornou mercadoria e uma profissionalização que, cienticizada, tornou-se o centro do paradigma político atual". (idem, p. 46)

A relação educação e novas tecnologias implicam, na contemporaneidade, o incremento da mais valia-relativa no trabalho do professor. Influenciando essa relação está o Banco Mundial que já no final da década de 1960, preconizava a "revolução tecnológica" 
à indústria da educação como meio de aumentar a produtividade dos "bons professores", como vemos nas palavras do então presidente do Banco Mundial, McNamara citado por Silva (2002).

É importante sublinhar que a indústria da educação, normalmente entre as maiores empregadoras de qualquer país, é uma das poucas que não sofreram uma revolução tecnológica. Precisamos retirá-la do estágio artesanal. Dada a terrível insuficiência, que tende a agravar-se, de professores qualificados, é preciso encontrar os meios de aumentar a produtividade dos bons professores. Isto incluirá investimentos em livros didáticos, em materiais audiovisuais e, sobretudo, no emprego de técnicas modernas de comunicação rádio, filmes e televisão no ensino. (p. 110)

A influência dos gestores do Banco Mundial nas decisões educacionais, segundo Silva (2002 e 2003), pode ser constatada nas pressões sobre o governo brasileiro e a presença de um pensamento que direciona o processo decisório. A autora apresenta vários exemplos e dentre eles destacamos a redução de custos e a priorização da educação básica, deixando à iniciativa privada os demais níveis de ensino.

Sobre essa privatização da educação Robertson e Dale (2011) argumentam que o processo que transforma o conhecimento em mercadoria pelo Banco Mundial "representa uma significativa erosão da educação como algo que constitui um público e um setor público.” (p. 43)

Lembramos aqui o pensamento de Marx na Crítica ao Programa de Gotha (1977) (sobre o papel do Estado na Educação e sua recusa em aceitar sua ingerência no ensino do povo) e entendemos que o mesmo se pode afirmar quanto ao Banco Mundial.

Ademais, analisando a influência dos Organismos Multilaterais no país, Frigotto (1984), argumenta que a visão tecnicista da educação responde à ótica economicista do ensino veiculada pela teoria do "capital humano" e constitui-se numa das formas de desqualificação do processo educativo escolar.

Saviani (2007) corrobora essa tese, destacando que a perspectiva tecnicista é desde a década de 1990 neotecnicista e emerge como mecanismo de recomposição dos interesses burgueses na educação. Assim, o tecnicismo/neotecnismo se articula com o parcelamento do trabalho pedagógico, decorrente da divisão social e técnica do trabalho no interior do sistema capitalista de produção.

Para Saviani (2007), a "pedagogia do aprender a aprender", tem o "objetivo de dotar os indivíduos de comportamentos flexíveis que lhes permitam ajustar-se às condições de uma sociedade em que as próprias necessidades de sobrevivência não estão garantidas" (idem, p. 435)

Transferida a responsabilidade dos empregos pelo Estado de bem-estar social para os próprios indivíduos sob o Estado Mínimo, Saviani conclui que essa transferência os tornam subjugados à "mão invisível do mercado" . (idem)

As empresas, sob a "pedagogia das competências", exigem trabalhadores formados nessa perspectiva, pressionando, assim, as escolas que mudam o currículo "do conhecimento das disciplinas de conhecimento para o ensino de competências referidas à situações determinadas." (idem, p. 436). E a partir de Marx, Saviani teoriza que ser produtivo não significa apenas produzir mais mercadorias mas "criar valor de troca, isto é, mais-valia" (idem, ibidem).

Para Saviani, desde os anos 1990 que nós não conseguimos escapar do neotecnicismo, que se faz presente alimentando a busca da qualidade total na educação e com a penetração da pedagogia corporativa. 
Ademais, os dados empíricos revelam um aumento acentuado do problema do professor leigo no país. Se em 2002, como vimos, o Brasil tinha 45.155 professores leigos para serem capacitados (cf. Inep), em 2009 esse número saltou para 152.454 ou, 7, 7\% dos docentes, enquanto que em 1999, no início do PROFORMAÇÃO, existiam 68.855 professores não-habilitados ou leigos, correspondendo a 2,87\% dos professores. Isso nos leva a julgar que essa política pública teve efetividade social e qualidade reduzidos, pois o problema do professor leigo piorou.

\section{Considerações finais}

Apesar do programa ter sido representado favoravelmente na subjetividade das professoras-trabalhadoras, os resultados do PROFORMAÇÃO não causaram o impacto prometido no país, haja vista o aumento de 7,7\% dos professores leigos no ano de 2009 , constatado pelo INEP.

Enquanto modelo de educação a distância, este programa utilizou-se da pedagogia do aprender a aprender, da competência e da avaliação em todo o processo, alicerçado no material didático autoinstrucional e nos vídeos auxiliados por tutores, com formação aligeirada.

Apesar de reconhecer esse aligeiramento da formação do tutor, Andrade (2011) propõe que o modelo do PROFORMAÇÃO seja adotado por outras políticas públicas de formação de professores. De certa forma é isso o que vemos que está acontecendo com as outras políticas de educação a distância no país, como por exempolo na Universidade Aberta do Brasil, UAB quando o professor se aliena do seu saber ao passar a ser conteudista numa divisão de tarefas que o planejamento centralizado e neotecnicista do MEC lhe impõe.

O PROFORMAÇÃO, em suma, é um programa criado sob a ótica do Estado reformador voltado para a maximização da técnica e dos técnicos. No seu modelo educacional há um vínculo direto entre educação e produção capitalista, que prioriza as competências e habilidades técnicas ao invés do conhecimento e ética política, acentuando, portanto, a alienação do professor-trabalhador.

\section{Referências}

ANDRADE, Luciane Sá de. Formação de Professores em nível médio na modalidade a distância: a experiência do PROFORMAÇÃO. Campinas: Autores Associados, 2011.

AUGUSTO, Ubirajara José. Políticas Públicas para a Educação a Distância: O caso do PROFORMAÇÃO no Município de Formosa, Goiás. 2005. 120 f. Dissertação (Mestrado em Educação) - Universidade de Brasília.

BARRETTO, Elba Siqueira de Sá. Novas Políticas Educacionais para velhas escolas rurais.Um estudo de caso no sertão do Piauí. Cadernos de Pesquisa, São Paulo, 46, p. 23 49, ago, 1983.

BRASIL. MEC. Planejamento político-estratégico 1995/1998. Brasília, DF, 1995.

BRASIL. MEC. Boletins Técnicos do FUNDESCOLA. Brasília, DF. 1997-1999. 
BRASIL. Ministério da Educação e do Desporto, MEC. Secretaria de Educação a Distância, SEED. Programa de Formação de Professores em Exercício. Disponível em: <http://www.mec.gov.br/seed/proform> Acesso em: 18 de fevereiro de 2006.

BRASIL. Ministério da Educação e do Desporto, MEC. Secretaria de Educação a Distância, SEED. Programa de Formação de Professores em Exercício. Disponível em: <http://proformacao.proinfo.mec.gov.br/historico.asp> Acesso em 09 de agosto de 2011.

BRASIL. Proformação : avaliação externa / pesquisadoras responsáveis Vera Maria N. S. Placco, Marli E. D. A. André, Bernadete A. Gatti. - Brasília: MEC/SEED - Secretaria de Educação a Distância, 2003.

BRASIL. MENEZES, Mindé; RAMOS, Wilsa M (Orgs). PROFORMAÇÃO: Guias de Estudo. Brasília: MEC/FUNDESCOLA, 2004. . Manual de Operacionalização do PROFORMAÇÃO. 4ª ed. Brasília: MEC/FUNDESCOLA, 2004.

BELLONI, Maria Luisa. Educação a Distância. Campinas:Autores Associados, 1999.

BOF, Alvana M.; SALGADO, Maria U. C; MOORE, Michael G.; MENEZES, Mindé B; RAMOS, Wilsa M. O PROFORMAÇÃO: Proposta Pedagógica, Estrutura e Implementação. $A B E D$. Disponível em: http://www2.abed.org.br/visualizaDocumento.asp?Documento_ID=70 Acesso em 18/12/2011.

FRIGOTTO, Gaudêncio. A produtividade da escola improdutiva. São Paulo: Ed. Cortez \& Autores Associados, 1984.

FOLHA DIRIGIDA, 04/06/2010. Rede privada possui mais professores "leigos".

Disponível em:

$<$ http://ultimosegundo.ig.com.br/educacao/rede+privada+possui+mais+professores+leigos/

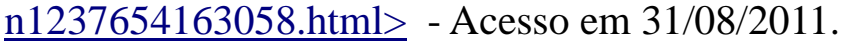

FONSECA, Marilia. Banco Mundial e Educação a Distância. In: PRETTO, Nelson L. Globalização \& Educação. 2. Ed. Ijuí: :Unijuí, 1999, p. 59-77.

GATTI, Bernadete. FORMAÇÃO CONTINUADA DE PROFESSORES: A QUESTÃO PSICOSSOCIAL Cadernos de Pesquisa, n. 119, julho/ 2003, p. 191-204.

KAWAMURA, Lili K. Tecnologia e Política na Sociedade: Engenheiros, Reivindicação e Poder. São Paulo: Brasiliense, 1986.

Novas tecnologias e educação. São Paulo: Ática, 1990. (Série Princípios)

MARX, Karl. Contribuição para a crítica da economia política (Prefácio). Lisboa, Estampa, col. Teoria, 1971.

MARX, K.; ENGELS, F. Textos, (1) (Crítica ao Programa de Gotha). São Paulo: AlfaÔmega, 1977.

MORAES, Raquel de A. Banco Mundial, formação de professores e informática na educação. Revista Linhas Críticas, Brasília, v. 7 n. 12, jan./jun. 2001, p. 99-112.

MORAES, R. De. A.PROFORMAÇÃO: uma análise da influência do Banco Mundial na formação dos professores leigos. Revista Linhas Críticas, Brasília, v. 9, n. 17, 2003, p. 295-308. 
MORAES, R. A; LIMA, Carlos A F. A política de formação de professores leigos no Brasil: o PROFORMAÇÃO. Universidade e Sociedade, Brasília/DF, Ano XV, n. 36, jul. 2005, p. 73-80.

ROBERTSON, Suzan L; DALE, Roger. O Banco Mundial, o FMI e as possibilidades da Educação Crítica. In: APPLE, M. W.; AU, W.;GANDIN. L.A.Educação Crítica: Análise Internacional. Porto Alegre: Artmed, 2011, p. 34-48.

SAVIANI, Dermeval. O trabalho como princípio educativo frente às novas tecnologias. In: FERRETI, Celso et. Al. (Orgs.) Novas Tecnologias, Trabalho e Educação.Petrópolis:Vozes, 1994, p. 147-164.

SAVIANI, Dermeval. Pedagogia Histórico-Crítica.Primeiras Aproximações. ${ }^{\mathrm{a}} \mathrm{ed}$. Campinas, SP: Autores Associados, 2003.

. História das Idéias Pedagógicas no Brasil. Campinas: Autores Associados, 2007.

Sistema Nacional de Educação articulado ao Plano Nacional de Educação.Revista Brasileira de Educação v. 15 n. 44 maio/ago. 2010, p.380-412.

SCAFF, Elisângela A. S. Os organismos internacionais e as tendências para o trabalho do professor. Campo Grande, MS: Editora, 2000.

SILVA JUNIOR, João dos Reis; KATO, Fabíola B. G.; SANTOS, Silvia A . In: SOUZA et Al.Educação a Distância: Diferentes abordagens críticas. São Paulo: Xamã, 2010, p. 33 52.

SILVA, Maria Abadia . Intervenção e Consentimento: a política educacional do Banco Mundial. 1. ed. Campinas: FAPESP / AUTORES ASSOCIADOS, 2002. v. 2002.

Do projeto político do Banco Mundial ao Projeto político pedagógico da escola pública brasileira. Cadernos do CEDES (UNICAMP), Campinas- São Paulo, v. 23, n. 61, p. 283-301,2003.

SORDI, M.R. A face perversa da avaliação: elementos para uma leitura do papel da avaliação no projeto neoliberal. In: Avaliação/Rede de Avaliação Institucional de Educação Superior - RAIES, Revista trimestral da Rede. Campinas, Unicamp, 1998, p. 51-58.

SOUZA, José Nicolau de. Edurural / NE e a proposta pedagógica adaptada ao meio rural: a teoria se confirma na prática? / José Nicolau de Souza . - Natal (RN), 2001, 256 p.(Tese de Doutorado), UFRN.

TOMMASI, Livia; WARDE, Mirian; HADDAD, Sérgio (Orgs.): o Banco Mundial e as Políticas Educacionais. 2 Ed., São Paulo: PUC-SP e Cortez, 1998.

YAZBECK, D. C. Avaliação Educacional Básica: por entre alguns projetos que tecem a história e os caminhos da institucionalização. RBPAE. v 18, 2002, p.245-260.

WORLD BANK. Lifelong Learning in the Global Knowledge Economy: Challenges for Developing Countries. A World Bank Report. Washington, 2003.

WORLD TRADE ORGANIZTION (WTO). Council for Trade in Services Special Session. Communication from the United States: higher (tertiary) education, adult education and training. 2000. (S/CSS/W/23, 18 Dec. 2000). Disponível em: <www.unesco.org/ education/studyingabroad/highlights/global_forum/gats_he/us.pdf $>$. 


\section{Notas}

* Doutora em Educação e Professora Associada do Programa de Pós-Graduação em Educação, da Faculdade de Educação, UnB, rachel@unb.br

A extinção da SEED-MEC ocorreu, segundo a Folha Dirigida, no dia 18 de janeiro de 2011, em consequência das diversas alterações em sua estrutura desde a saída de Carlos Eduardo Bielschowsky, no final de 2010, que culminaram na sua desativação.

2 O FUNDESCOLA foi precedido pelo Programa Nordeste II em 1997 , que foi precedido pelo EDURURAL ou Nordeste I, Programa de Expansão e Melhoria do Ensino no Meio Rural no Nordeste Brasileiro, implementado pela Fundação Carlos Chagas e o Banco Mundial.

3 Para Marília Fonseca (2000, p. 60-62), o Banco Mundial, BM foi criado em 1944, nos EUA, juntamente com o FMI, com a tarefa de reconstruir a Europa, auxiliando os países devastados pela guerra a recuperarem suas economias. Enquanto ao FMI foi conferida uma tarefa mais política, o BM funcionava como um emprestador de recursos para projetos específicos. Passado o momento da reconstrução, as duas entidades passaram a monitorar o desenvolvimento do chamado Terceiro Mundo. A princípio, o Banco Mundial era composto apenas por países sócios, mas quando começou a monitorar o Terceiro Mundo, passou a existir uma desigualdade financeira afetando as relações de poder dentro do Banco, já que o poder de voto é proporcional ao aporte de recursos de cada país. Assim, o Brasil, apesar de ser um paíssócio "não tem um voto poderoso e, muito menos, o poder de modificar as regras do Banco, visto que os cinco grandes países, EUA, Japão, Alemanha, França e Inglaterra, nessa ordem, têm direito a 40\% dos votos no Banco Mundial" (idem, p. 62).

O MOODLE é o acrônimo de Modular Object-Oriented Dynamic Learning Environment. Moodle também ganha significado como uma nova palavra que indica uma forma de aprender, que utiliza a pedagogia construcionista social (para maiores detalhes ver o link_<http://docs.moodle.org/en/Philosophy>-

5 TSME - Acrônimo de Técnico da Secretaria Municipal de Educação, entrevistado número 2.

Recebido em: $\quad$ 23/09/11

Aprovado em: $19 / 12 / 11$ 